\title{
A HYBRID TECHNOLOGY FOR Pt-Rh AND SS316L HIGH POWER MICRO-RELAYS
}

\author{
F.M. Ozkeskin ${ }^{1 *}$ and Y.B. Gianchandani ${ }^{1,2}$
}

${ }^{1}$ Department of Mechanical Engineering, University of Michigan, Ann Arbor, USA

${ }^{2}$ Department of Electrical Engineering and Computer Sciences, University of Michigan, Ann Arbor, USA

\section{ABSTRACT}

This paper reports a hybrid technique to microfabricate relays from platinum-rhodium and stainless steel $316 \mathrm{~L}$ bulk foil and to directly assemble them on printed circuit boards with gold coated copper interconnect for high power handling capability. Devices of $6 \mathrm{~mm}^{2}$ size serve as relays for DC current levels $>1 \mathrm{~A}$, and are suitable for circuits dissipating $>250 \mathrm{~W}$ power.

\section{BACKGROUND AND ADVANCES}

The most commonly used processes for microsystem device manufacturing and assembly rely upon semiconductor technology and silicon based substrates. Although these processes are mature, the properties of silicon are seldom adequate for high power applications; additionally environmental limitations impose significant burden upon hermetic packaging of silicon based devices. Recent research reports have described device microfabrication on non-silicon substrates such as printed circuit boards (PCBs) and liquid crystal polymer to ease packaging and system integration [1-3]. Semiconductor based fabrication techniques typically provide very limited access to metal alloys, relying more on thin film sputtering [4-5], which limits the powerhandling capability of the components. A hybrid technology by which hard metal alloy devices can be fabricated from bulk robust metal foils is of interest.

Micro-electrodischarge machining $(\mu \mathrm{EDM})$ provides a lithography compatible manufacturing method for bulk metal foil based micro devices with feature sizes down to $5 \mu \mathrm{m}$. Both serial and batch mode machining have been developed and characterized in our group [6]. A $\mu$ EDM'ed oscillating micro-relay on a glass substrate was also reported earlier [7]. This paper presents a hybrid technique whereby hard metal bulk foils such as platinumrhodium (Pt-Rh) and stainless steel 316L (SS316L) are first $\mu$ EDM'ed, then assembled on PCBs to demonstrate high power DC switching capability without compromising device footprint.

\section{DESIGN}

The central element of the device is an electrostatically actuated cantilever beam that is assembled on a power-rated PCB. The bulk metal foil cantilever $(2400 \mu \mathrm{m} \times 950 \mu \mathrm{m} \times 40 \mu \mathrm{m})$ provides mechanical robustness and chemical resistance to corrosion. In particular, Pt-Rh prevents adhesion problems, and can withstand high temperatures without softening, alloying or microwelding to the contact surface. A lower cost alternative, SS316L, is used for benchmarking.

The cantilever beam is orthogonally placed with respect to the signal line, being suspended above a break in a PCB metal trace (Figure 1), and anchored by alignment posts that perforate it; these posts are positioned in blind vias on the PCB. A paddle at the distal end of the cantilever serves as an actuation (pull-down) electrode. Below it is a ground electrode, patterned on the PCB. The cantilever has two recessed zones: one over the ground electrode that is designed to prevent contact, and a shallower one over the signal line to ensure contact when it is actuated. This design also provides a protrusion that rests against stand-off bumps on the PCB, preventing contact between the pull-down electrode and the ground electrode.

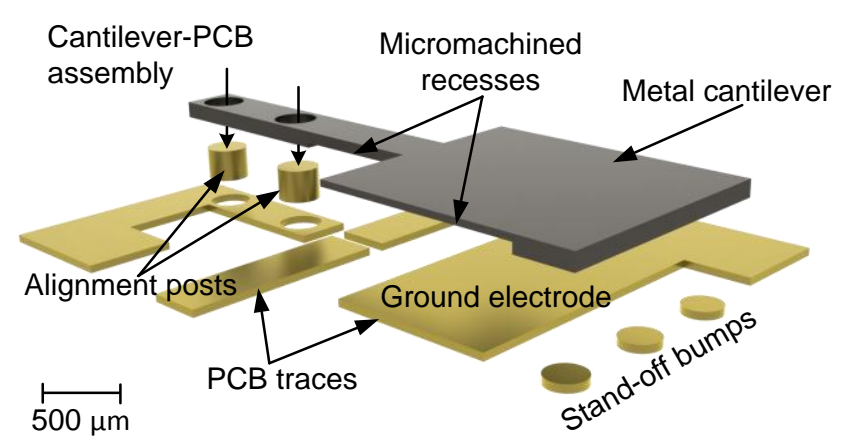

Figure 1: Exploded view of structure showing cantilever relay. Recesses are machined (2 $\mu \mathrm{m}$ across contact, $8 \mu \mathrm{m}$ across electrodes) for DC-contact switching. Gold posts align and hold the cantilever over gold-coated copper traces on the PCB.

\section{FABRICATION/ASSEMBLY Micro-Relays}

Micro-relays were fabricated in both Pt-Rh (80:20) and SS316L using $50 \mu \mathrm{m}$ thick stock metal foils. The patterns were serially $\mu$ EDM'ed. The lowest available discharge energy was used to ensure smooth surface finish. (Batch mode fabrication is also possible by using lithographically fabricated tool electrodes.) Perforations of $310 \mu \mathrm{m}$ diameter were located in the anchor regions for subsequent alignment and attachment to the PCB. Machined hole diameters were slightly larger than the tool electrode diameter due to EDM discharge gaps of $5 \mu \mathrm{m}$ in all directions.

\section{PCB}

A standard FR-4 with $1.6 \mathrm{~mm}$ thickness constituted the PCB substrate. $\mathrm{Cu}$ traces of $90 \mu \mathrm{m}$ thickness were chosen for high current ratings (up to $4.5 \mathrm{~A}$ for $300 \mu \mathrm{m}$ wide signal lines). In such PCBs, a $4 \mu \mathrm{m}$ Ni layer is sandwiched between a $\mathrm{Cu}$ base layer and a $0.15 \mu \mathrm{m}$ thick outer gold layer. Through holes formed by vias were positioned for subsequent assembly and electrical contact to the micro-relays.

\section{Assembly}

Alignment posts (1750 $\mu \mathrm{m}$ height; $300 \mu \mathrm{m}$ diameter), were $\mu$ EDM'ed as slices from gold wire. These were inserted as tight fits into the same diameter PCB vias by tweezers (Figure 2a). The length of the posts was designed to extend above the PCB trace by approximately $50 \mu \mathrm{m}$, to precisely accommodate the cantilever beam. The micro-relays were assembled into the posts by aligning over the posts (Figure 2b). A gold particle-filled conductive epoxy (Creative Materials, volume resistivity: $300 \mu \Omega-\mathrm{cm}$ ) was manually applied through a syringe around the alignment posts (Figure 2c). Other techniques such as the use of solder balls are optional. The flatness of the cantilever beam was maintained during the assembly process by monitoring the height of the beam tip from a laser displacement sensor (Keyence LK-G) and adjusting to ensure 
that the cantilever tip is in contact with stand-off bumps during the epoxy curing. An assembled device is shown in Figure 3.
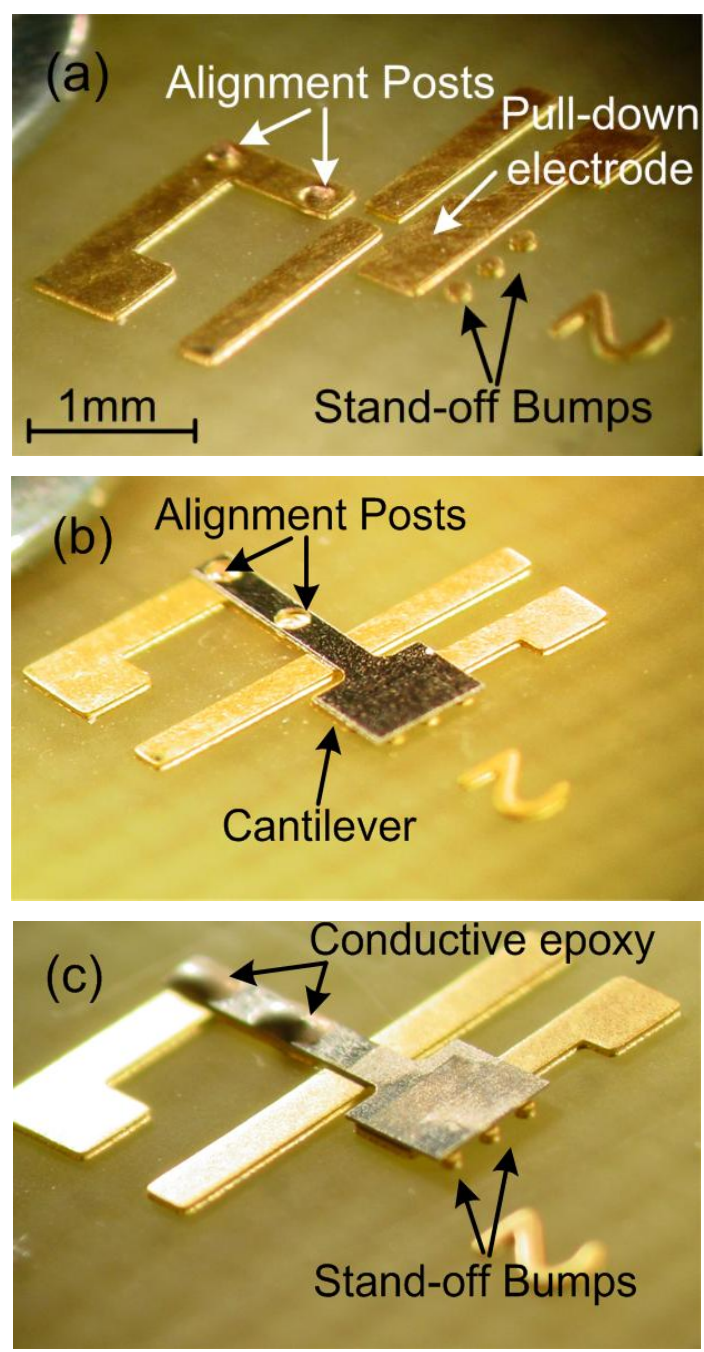

Figure 2: Assembly sequence for Pt-Rh and SS316L devices showing: (a) electrodes with alignment posts inserted. (b) The cantilever placed so that posts fit in vias in the thick foil. (c) Conductive epoxy applied for fixing.

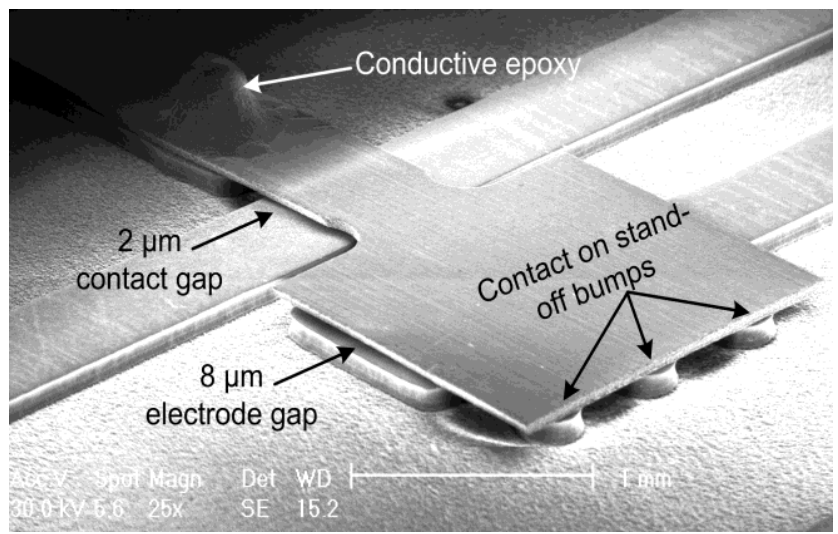

Figure 3: SEM image of the assembled device showing machined gaps, conductive epoxy and the stand-off bumps.

\section{TESTING}

The test circuit is shown in Figure 4a. It consists of a control voltage $\left(\mathrm{V}_{\mathrm{SS}}\right)$ and two sets of power-rated load resistors: $\mathrm{R}_{\mathrm{L} 1}$ and $\mathrm{R}_{\mathrm{L} 2}$ along with a standard high value resistor to ensure that current pathway is on the signal line. Voltage values in boxes: $V_{S}, V_{D}$ and $\mathrm{V}_{\mathrm{G}}$ indicate measurements taken. $\mathrm{V}_{\mathrm{G}}$ was always lower than 300 $\mu \mathrm{V}$, indicating good switch isolation due to stand-off bumps. For testing, two different circuit configurations with different load resistors were used, as described in Table1. These configurations tested different voltage and current limits. In addition, tests were conducted both in air and nitrogen ambient. Nitrogen tests were conducted in a 0.2 Torr vacuum chamber. All the tests were repeated for both Pt-Rh and SS316L devices.
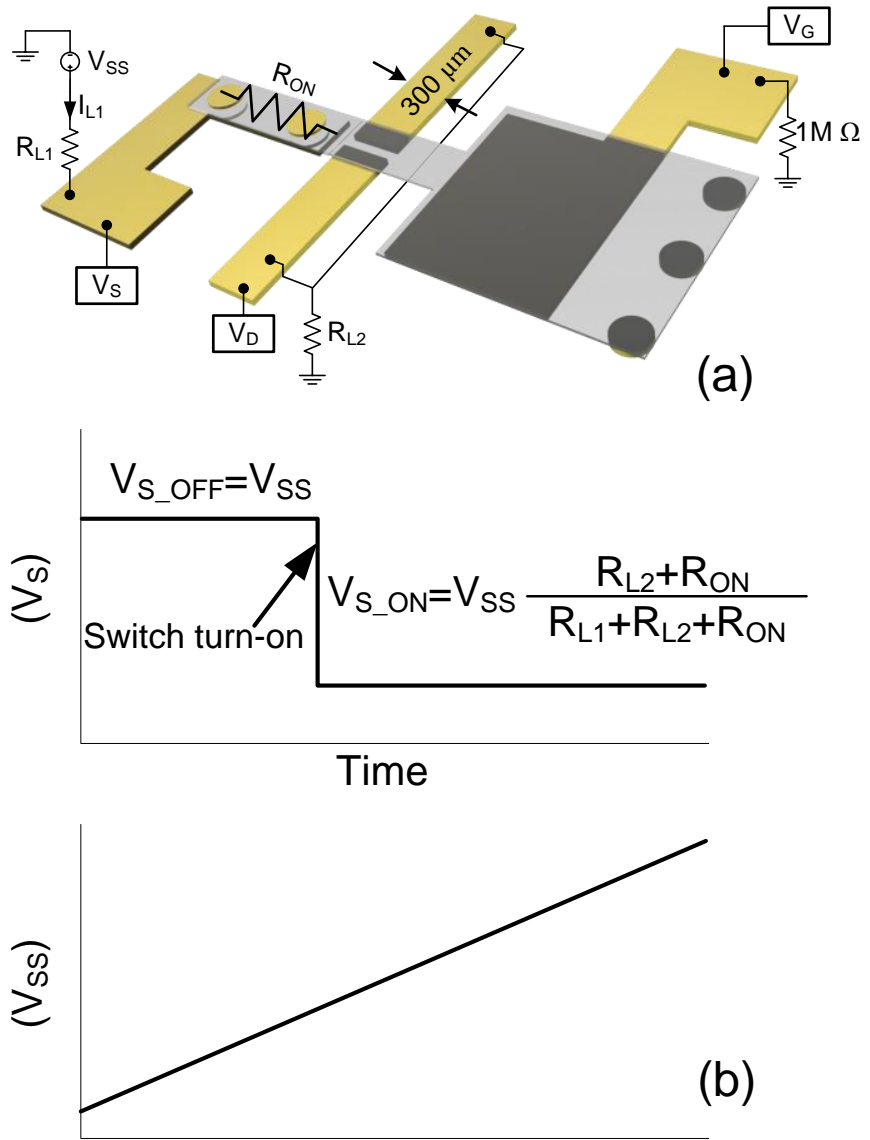

Time

Figure 4: (a) Circuitry for testing; voltages in boxes are for measurements. $V_{D}$ and $V_{S}$ are used to determine ON-state resistance $\left(R_{O N}\right)$. (b) The transient behavior of $V_{S}$ as $V_{S S}$ is progressively increased, showing $V_{S_{-} O F F}$ and $V_{S_{-} O N}$ conditions.

Table 1: Device test configuration details. Config1 provides higher voltage testing (>300 V) whereas Config2 is suited for high current (>1 A).

\begin{tabular}{|c|l|}
\hline Configuration & Description \\
\hline Config1 & $\mathrm{R}_{\mathrm{L} 1}=400 \Omega, \mathrm{R}_{\mathrm{L} 2}=125 \Omega, 0.6 \mathrm{~A}$ max. allowed current \\
\hline Config2 & $\mathrm{R}_{\mathrm{L} 1}=100 \Omega, \mathrm{R}_{\mathrm{L} 2}=83 \Omega, 1.34 \mathrm{~A}$ max. allowed current \\
\hline
\end{tabular}

$\mathrm{R}_{\mathrm{ON}}$ in Figure $4 \mathrm{a}$ is ON-state resistance and is a sum of the cantilever resistance and contact resistances at the epoxy transfer 
points. $\mathrm{R}_{\mathrm{ON}}$ can be reduced with improved contact materials.

Figure $4 \mathrm{~b}$ shows the transient response of $\mathrm{V}_{\mathrm{S}}$ to a progressive increase of $V_{S S}$. When the switch is in OFF-state, $V_{S}$ is the same as $\mathrm{V}_{\mathrm{SS}}$ (denoted as $\mathrm{V}_{\mathrm{S}_{\mathrm{O}} \mathrm{OFF}}$ ). When the switch is turned on and goes to $\mathrm{ON}$-state, $\mathrm{V}_{\mathrm{S}}$ is reduced sharply and is defined as a combination load resistors and $\mathrm{R}_{\mathrm{ON}}$ during $\mathrm{ON}$-state (denoted as $\mathrm{V}_{\mathrm{S}_{-} \mathrm{ON}}$ ).

\section{RESULTS}

Figure 5 shows $R_{\mathrm{ON}}$ as a function of series current in the circuit $\left(\mathrm{I}_{\mathrm{L} 1}\right)$ for 6 different test conditions that include the two types of relay materials, air and nitrogen environments, and the two different circuit load configurations presented in Table 1. In general, the Pt-Rh micro-relay offers the best overall performance, and in a nitrogen ambient, it can support $>1$ A DC current. The lowest recorded $\mathrm{ON}$-state resistance was $2.8 \Omega$. The current handling capability of Pt-Rh devices was tested to the point of failure in Config2 and nitrogen environment. Device failure for this configuration occurred at approximately $1.2 \mathrm{~A}$ due to excessive heating of the contacts causing microwelding. The switch was operated around 600 cycles before failure took place.

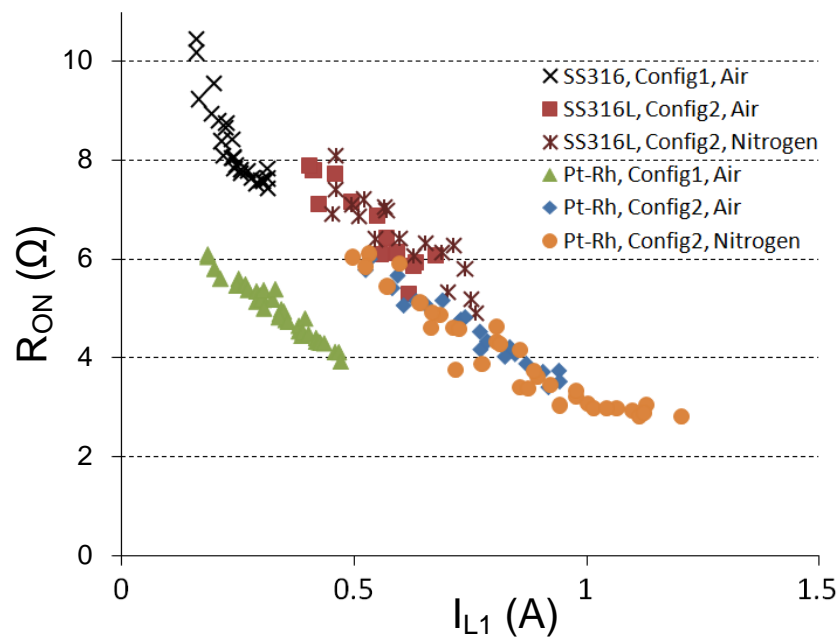

Figure 5: Switch ON resistance vs. series current. Highest current handling is for Pt-Rh in Nitrogen environment where $R_{O N}$ is $2.8 \Omega$.

Figure 6 shows $\mathrm{R}_{\mathrm{ON}}$ as a function of supply power $\left(\mathrm{P}_{\mathrm{SS}}\right)$, which is the circuit dissipated power, for the same 6 conditions aforementioned, indicating that these micro-relays can be used in circuits that dissipate $>250 \mathrm{~W}$ power. The switch failure occurring at $1.2 \mathrm{~A}$ current translates to $332 \mathrm{~W}$ of $\mathrm{DC}$ power for Pt-Rh, Config2 and nitrogen ambient. $\mathrm{P}_{\mathrm{SS}}$ is provided by $\mathrm{V}_{\mathrm{SS}} \mathrm{I}_{\mathrm{L} 1}$, i.e. the total power dissipated in the circuit.

Figure 7 shows the voltage $V_{S}$ at the anchor of the microrelay when it is turned on (denoted as $\mathrm{V}_{\mathrm{S} \text { ON }}$ ). This value is used to calculate the $\mathrm{R}_{\mathrm{ON}}:\left(\mathrm{V}_{\mathrm{S} \text { ON }}-\mathrm{V}_{\mathrm{D}}\right) / \mathrm{I}_{\mathrm{L} 1}$.

Switch actuation voltage $\mathrm{V}_{\text {SS }}$ was designed to be $100 \mathrm{~V}$. Test results, however indicate an actuation voltage of 107-110 V. Relatively small deviation (10\% maximum) of experimental value from theoretical value can be correlated to structural inperfections or circuit parasitics. Note that the supply voltage can be increased past 300V for Pt-Rh switches.

Figure 8 shows the typical transient response of a Pt-Rh micro-relay. Typical turn-on/turn-of times are 30-40 ms. The device can actuate faster with perforations on the actuation electrode paddle which would decrease air damping, however a compromise could be made with increased actuation voltage due to decreasing electrode overlap area.

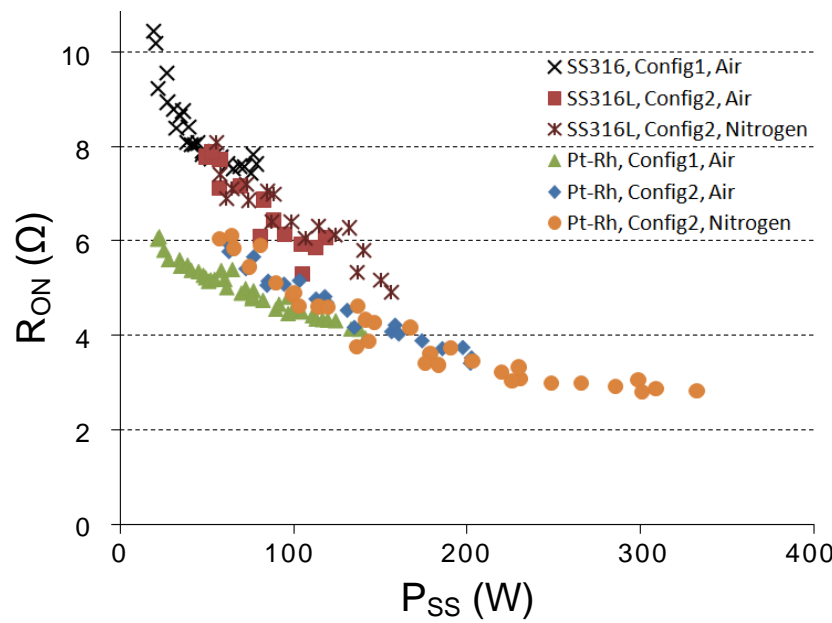

Figure 6: Switch ON $\left(R_{O N}\right)$ resistance vs. supply power $P_{S S}$ which goes up to $332 \mathrm{~W}$ for Pt-Rh switch. $P_{S S}$ denotes circuit dissipated power.

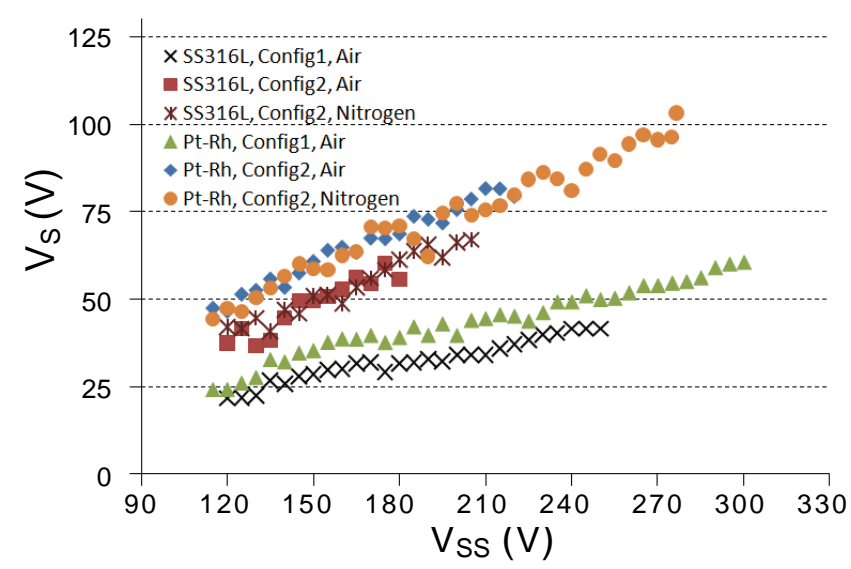

Figure 7: $V_{S}$ measurement for control values of $V_{S S}$. This $V_{S}$ is denoted by $V_{S_{-} O N}$ in Figure $4 b$.

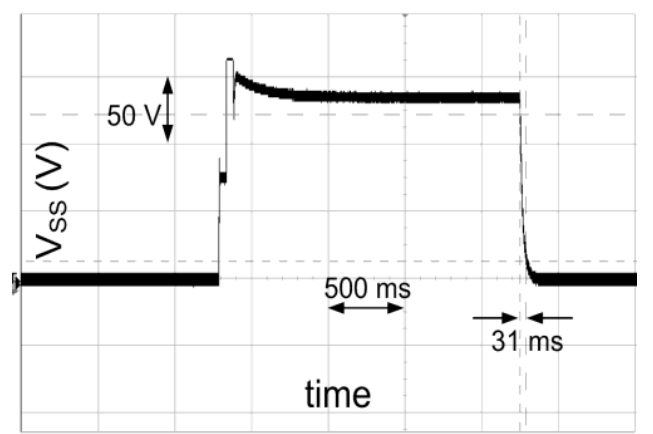

Figure 8: Switch response is shown for a $V_{S S}$ of $135 \mathrm{~V}$. The fall time measured is $31 \mathrm{~ms}$ and rise time is similar. 
Table 2: Switch performance and size comparison to solid state and MEMS relays. Pt-Rh metal cantilevers provide high current carrying capability and small footprint.

\begin{tabular}{|l|c|c|c|c|c|c|}
\hline \multicolumn{1}{|c|}{ Property } & \multicolumn{9}{c|}{ Devices } \\
\cline { 2 - 7 } & $\begin{array}{c}\text { SKKD } \\
57 / 08 \\
\text { Thyristor }\end{array}$ & $\begin{array}{c}\text { ISL9V } \\
\text { 2040S3S } \\
\text { IGBT }\end{array}$ & $\begin{array}{c}\text { SiC } \\
\text { Schottky } \\
\text { Diode }\end{array}$ & $\begin{array}{c}\text { Omron } \\
\text { MEMS } \\
\text { Switch }\end{array}$ & $\begin{array}{c}\text { Cronos } \\
\text { MEMS } \\
\text { Switch }\end{array}$ & $\begin{array}{c}\text { This Study } \\
\text { (Pt-Rh and } \\
\text { Config2) }\end{array}$ \\
\hline Footprint $\left(\mathrm{mm}^{2}\right)$ & 1302 & 112 & 303 & 15.6 & 36 & $\mathbf{6}$ \\
\hline Max current $(\mathrm{A})$ & 45 & 10 & 10 & 0.1 & 0.35 & 1.2 \\
\hline Current per $\mathrm{mm}^{2}\left(\mathrm{~A} / \mathrm{mm}^{2}\right)$ & 0.035 & 0.089 & 0.033 & 0.006 & 0.01 & $\mathbf{0 . 2}$ \\
\hline On resistance $(\Omega)$ & 0.005 & 0.6 & $0.1-0.15$ & 2 & 0.7 & 2.8 \\
\hline Actuation time $(\mathrm{ms})$ & 0.002 & 0.002 & 0.0001 & 0.02 & 10 & 30 \\
\hline
\end{tabular}

Table 2 benchmarks this work to cross-technology (solidstate) options as well as in-technology (MEMS) relays. Commercial solid state alternatives include a high power thyristor [8], an insulated-gate bipolar transistor (IGBT) [9], and a high power SiC Schottky diode [10]. MEMS counterparts include a commercially available switch [11] and a research device [12]. It can be seen that solid state devices often have very fast actuation times and higher current ratings; however, these devices require compromises on footprint. Available MEMS devices have smaller footprint, but also low current ratings. While $\mathrm{R}_{\mathrm{ON}}$ is larger for this work, the compactness is very competitive and the power handling is adequate for several applications.

\section{CONCLUSIONS}

A hybrid technology for fabrication and assembly of bulk foil hard metal high power micro-relays has been developed. Microelectrodischarge machined cantilevers were directly assembled on PCBs with gold coated power rated traces, to facilitate system integration. Fabricated Pt-Rh devices demonstrated up to $1.2 \mathrm{~A}$ of current rating, for operation in circuits dissipating $>250 \mathrm{~W}$ of DC power. The micro-relays have a footprint of $6 \mathrm{~mm}^{2}$ and provide high current rating per area compared to solid-state and MEMS counterparts.

\section{ACKNOWLEDGEMENT}

This study is supported in part by Defense Advanced Research Projects Agency, Microsystems Technology Office (DARPA MTO) contract \# W31P4Q-09-1-0009.

\section{REFERENCES}

[1] B.S. Weber and L.C. Kretly, "PCB-MEMS RF Switch: Parametric analysis and design guide lines," IEEE MTT-S International Microwave Theory and Techniques Symposium Proc. (2007), pp. 141-144.

[2] M. Maddela and R. Ramadoss, "A MEMS-based tunable coplanar patch antenna fabricated using PCB processing techniques," Journal of Micromechanics and Microengineering, 17 (2007), pp. 812-819.

[3] R. Dean, J. Weller, M. Bozack, B. Farrell, L. Jauniskis, J. Ting, D. Edell and J. Hetke, "Micromachined LCP connectors for packaging MEMS devices in biological environments," Journal of Microelectronics and Electronic Packaging, 4, 1 (2007), pp. 17-22.

[4] H. Lee, R.A Coutu, S. Mall and K.D. Leedy, "Characterization of metal and metal alloy films as contact materials in MEMS switches," Journal of Micromechanics and Microengineering, 16 (2006), pp. 557-563.
[5] R.A. Coutu, P.E. Kladitis, K.D. Leedy, and R.L. Crane, "Selecting metal alloy electric contact materials for MEMS switches," Journal of Micromechanics and Microengineering, 14 (2004), pp. 1157-1164.

[6] K. Takahata and Y.B. Gianchandani, "Batch Mode Micro-Electro-Discharge Machining," Journal of Microelectromechanical Systems, 11, 2 (2002), pp. 102-110.

[7] K. Udeshi, and Y. B. Gianchandani, "A DC-powered highvoltage generator using a bulk Pt-Rh oscillating micro-relay", IEEE International Conference on Solid-State Sensors and Actuators (Transducers '07) (2007), pp. 1151-1154.

[8] http://www.semikron.com/internet/webcms/online/asim/0789 4300_DS.pdf, referenced November 2009.

[9] http://www.fairchildsemi.com/ds/IS/ISL9V2040D3S.pdf, referenced November 2009.

[10] http://www.cree.com/products/power_docs2.asp, referenced October 2009.

[11] http://www.components.omron.com/components/web/PDFLI B.nsf/0/9AAA9A30064393CA862574F80078809C/\$file/SB_ RFMEMS-02+SalesBrochure.pdf, referenced February 2010.

[12] R. D. Streeter, C. A. Hall, R. Wood and R. Madadevan, "VHF high-power tunable RF bandpass filter using microelectromechanical (MEM) microrelays," International Journal of RF \& Microwave CAE, 11, 5 (2001), pp. 261-275.

\section{CONTACT}

*F.M. Ozkeskin, tel: +1-979-218-1087; ozkeskin@umich.edu 